2003-01-01

\title{
A stochastic frontier approach to total factor productivity measurement in Bangladesh crop agriculture, 19611992
}

\section{Coelli, T}

http://hdl.handle.net/10026.1/4031

\subsection{2/jid.975 \\ Journal of International Development \\ Wiley}

All content in PEARL is protected by copyright law. Author manuscripts are made available in accordance with publisher policies. Please cite only the published version using the details provided on the item record or document. In the absence of an open licence (e.g. Creative Commons), permissions for further reuse of content should be sought from the publisher or author. 


\title{
A Stochastic Frontier Approach to Total Factor Productivity Measurement in Bangladesh Crop Agriculture, 1961 - 1992 ${ }^{1}$
}

\author{
Tim Coelli \\ School of Economics \\ University of Queensland, Brisbane, Australia \\ Sanzidur Rahman \\ School of Economic Studies \\ University of Manchester, Manchester, UK
}

and

\section{Colin Thirtle*}

Department of Environmental Science and Technology

Imperial College of Science, Technology and Medicine, University of London, London SW7 2BP

Department of Agricultural Economics, Extension and Rural Development, University of Pretoria, Pretoria 0002, RSA

Phone: 0207594 9337: Fax: +44-207-594-9334: Email: C.Thirtle@ic.ac.uk

* Corresponding author.

1 This paper is developed from Sanzidur Rahman's Ph.D. thesis, which was completed at the Asian Institute of Technology in 1998. We thank the Government of Japan for the financial support that made the collection of these data possible. This paper was written when Coelli and Rahman were visiting the Department of Agricultural and Food Economics at the University of Reading. We thank the United States Department of Agriculture for funding them both. Finally, we are indebted to tow anonymous referees whose comments have improved the paper considerably. 


\section{A Stochastic Frontier Approach to Total Factor Productivity Measurement in Bangladesh Crop Agriculture, 1961 - 1992}

Abstract: This paper applies a stochastic production frontier model to measure total factor productivity growth, technical efficiency change and technological change in Bangladesh crop agriculture for the 31 observations from 1960/61 to 1991/92, using data for 16 regions. The results reveal that technical change followed a U-shaped pattern, rising from the early 1970s, when the green revolution varieties were adopted, giving an overall rate of technical progress at 0.27 percent per year. However, technical efficiency declined throughout, at an estimated annual rate of 0.47 percent. The combined effect of slow technical progress, dominated by the fall in technical efficiency resulted in total factor productivity (TFP) declining at a rate of 0.23 percent per annum, with the rate of decline increasing in the later years. TFP change is shown to depend on the green revolution technology and agricultural research expenditures.

JEL Classification: O47, Q16, and C23.

Keywords: Stochastic frontier, total factor productivity, technical change, efficiency, Bangladesh.

\section{$1 \quad$ Introduction}

Agriculture is the major source of livelihoods in Bangladesh, accounting for more than one third of national income and employing about two-third of the labour force (McIntire, 1998). The sector is dominated by crop production, particularly rice. Being one of the most densely populated nations of the world the land-population ratio is highly unfavourable, resulting in poor food security and widespread hunger (Ahmed and Sampath, 1992).

Consequently, national policies have been directed towards transforming agriculture through rapid diffusion of modern varieties of rice and wheat, including the provision of the modern inputs needed to support such a strategy. This has led to an increase in fertiliser use, from $8.8 \mathrm{kgs}$. of nutrient per hectare in 1970 , to $48.3 \mathrm{kgs}$ per hectare in 1994 . There has been a three-fold rise in pesticide use, from 2,200 metric tons in 1982 , to 6,500 metric tons in 1994 , and the area under modern irrigation rose from zero in 1950 , to 23.7 percent of the gross cropped area in 1994 (Rahman, 1998).

As a result, food grain (rice and wheat) production grew at a rate of $3.25 \%$ per annum from 
1948 to 1994 , as compared with a population growth rate of $2.45 \%$ a year from 1950 to 1994 (Rahman, 1999). Thus, Bangladesh has been a food deficit country, but food imports have been kept within 10 percent of domestic demand since the 1970s, with occasional self-sufficiency in one or two recent years.

However, it has been suggested that the productivity growth from new agricultural technology is declining and that this trend is a threat to sustainable economic development in Bangladesh (Alauddin and Tisdell, 1991). Although overall food production steadily increased, the yield of modern rice varieties declined from 3.6 tons per hectare in 1969 to 2.4 tons in 1994 (Rahman, 1999). To some extent, this decline is the result of the spread of the single family of successful varieties to less suitable land, but increased intensity and the short stemmed modern varieties have combined to reduce soil fertility, since less biological material is returned to the land (Rahman, 1999). Thus, although yields and the level of use of modern inputs in Bangladesh agriculture is far lower than average world levels, the scope for increasing input use levels with a declining yield trend is limited. Therefore, output growth to meet the growing demand for food must rely on improvements in technology and efficiency.

Studies on total factor productivity (TFP) growth in Bangladesh crop agriculture are limited to the work of Pray and Ahmed (1991) and Dey and Evenson (1991), which both use the Tornqvist-Theil index approach. Since this formulation assumes technical efficiency, the changes in TFP have not been decomposed into technological progress and technical efficiency changes. This study fits a translog stochastic frontier production function to panel data on 16 regions, for the 31-year period from 1961 to1992. Since the modern variety that was introduced in the mid 1960s, diffused more rapidly in the 1970s, and slowed in the 1980s, this period covers the effects fully. The parameters of the stochastic frontier provide estimates of the changes in technical efficiency and technical progress as well as TFP, allowing policy implications to be inferred.

The next section of this paper outlines the methodology used to derive the TFP index from the 
stochastic frontier estimates. Section three describes the data and section four the estimation and hypothesis tests. The results are reported in section five and six discusses the TFP index and its elements. Section seven analyses the causes of change in efficiency, technical change and TFP and eight concludes with some policy inferences.

\section{$2 \quad$ Methodology}

The stochastic frontier production function for panel data can be written as:

$$
Y_{i t}=\exp \left(x_{i t} \beta+V_{i t}-U_{i t}\right)
$$

where $Y_{i t}$ is production in year $t(t=1,2, \ldots, 31)$ for region $i(i=1,2, \ldots ., 16) ; \beta$ is the vector of parameters to be estimated; the $\mathrm{V}_{\mathrm{it}} \mathrm{s}$ are the error component and are assumed to follow a normal distribution $\mathrm{N}\left(0, \sigma^{2}\right)$; the $\mathrm{U}_{\mathrm{it}} \mathrm{s}$ are non-negative random variables, associated with technical inefficiency in production, which are assumed to arise from a normal distribution with mean, $\mu$ and variance, $\sigma_{u}^{2}$, which is truncated at zero. The model used here incorporates a simple exponential specification of the time-varying inefficiencies, following Battese and Coelli (1992).

The technical efficiency of production for the $i^{\text {th }}$ region at the $t^{\text {th }}$ year can be predicted using (2) (Coelli et al., 1998):

$$
T E_{i t}=E\left[\exp \left(-U_{i t}\right) \mid\left(V_{i t^{-}} U_{i t}\right)\right]
$$

Technical efficiency change $\left(E C_{i t}\right)$ is then calculated as:

$$
E C_{i t}=T E_{i t} / T E_{i s}
$$

An index of technological change $\left(T C_{i t}\right)$ between two adjacent period $\mathrm{s}$ and $\mathrm{t}$ for the $\mathrm{i}^{\text {th }}$ region can be directly calculated from the estimated parameters of the stochastic production frontier. The partial derivatives of the production function are evaluated with respect to time at $\mathrm{x}_{\mathrm{it}}$ and $\mathrm{x}_{\mathrm{is}}$. We then converted these into indices and calculated their geometric mean. Following Coelli et al., (1998), the calculation of the technical change index is:

$$
T C_{i t}=\left\{\left[1+\frac{\partial f\left(x_{i s}, s, \beta\right)}{\partial s}\right] \times\left[1+\frac{\partial f\left(x_{i t}, t, \beta\right)}{\partial t}\right]\right\}^{0.5}
$$


The indices of technical efficiency change and technological change obtained by using equation (3) and (4) respectively can be multiplied to obtain a TFP index:

$$
T F P_{i t}=E C_{i t} * T C_{i t}
$$

which is equivalent to the decomposition of the Malmquist index suggested by Fare et al. (1985).

\section{$3 \quad$ Data and Variables}

The data used for this analysis are adapted from Deb (1995). Those used for estimating the stochastic production frontier are:

Aggregate crop Includes all seasons and varieties of rice (Aus, Aman, and Boro), wheat, jute, output sugarcane, potato, pulses, and oilseeds for each region. The variable is measured in values ('000 taka) estimated at constant 1984/85 prices.

Labour Labour engaged in agriculture is constructed from census data using a linear trend extrapolation model.

Land area Area (in hectares) under all crops included in output is considered as the land area under cultivation. This measure of land area allows for changes in cropping intensity.

Animal power Number of draft animals is estimated using linear trend extrapolation from the livestock census data.

Fertiliser Total value of fertilizers (urea, phosphate, potash, and gypsum) distributed to each region at 1984/85 prices.

Time Time trend1961-1992.

Dummy1989 Dummy variable to capture drop in output due to severe flooding of 1988 when 64 percent of the land resources were flooded for a period of 2-8 weeks with huge damage to crops, infrastructure and human life. 
The variables used to explain the TFP, technical change and technical efficiency indices are:

Green revolution Product of the proportion of area under modern varieties of rice and wheat and technology proportion of area under modern irrigation, used to capture the impact of green revolution technology. The multiplicative term is used to break the multicollinearity involved in these two variables, as access to irrigation entails expansion of modern variety cultivation. The estimated correlation coefficient between modern variety and irrigation indices is 0.84 .

Education Average years of schooling of the rural male population $>10$ years of age.

Flood proneness Proportion of deep-water and mixed Aus-Aman rice area to total rice area.

Drought proneness Proportion of rice area under broadcast Aus rice area to total rice area.

Infrastructure $\quad$ Kilometers of paved road per unit cropped area.

Extension $\quad$ Extension expenditure per farm (Taka per farm).

expenditure

Research

Technology adopted at farm level depends on the technology generated by the expenditure research system and there is a time lag involved from the point of technology generation to adoption. In order to take the lag into account, the weighted sum of research expenditures over a period of 14 years was used. The research variable is constructed as $\Sigma \mathrm{W}_{\mathrm{t}-\mathrm{i}} \mathrm{R}_{\mathrm{t}-\mathrm{i}}$, where $\mathrm{W}_{\mathrm{i}}$ is a weight and $\mathrm{R}_{\mathrm{t}-\mathrm{i}}$ is research investment in year t-i measured at constant $1984 / 5$ prices. The weight for the current year research expenditure is zero, for one year lag, 0.2 while for 2 years lag it is 0.4 and so on (for details, see Dey and Evenson, 1991).

\section{$4 \quad$ Estimation and Hypothesis Tests}

First, the functional form of the stochastic frontier is determined by testing the adequacy of the 
Cobb Douglas relative to the less restrictive translog. These frontier models are defined as

$$
Y_{i t}=\beta_{0}+\sum_{j=1}^{5} \beta_{j} x_{j i t}+\delta D_{i t}+V_{i t}-U_{i t}
$$

and

$$
Y_{i t}=\beta_{0}+\sum_{j=1}^{5} \beta_{j} x_{j i t}+\sum_{j=1}^{5} \sum_{k=1}^{5} \beta_{j k} x_{j i t} x_{k i t}+\delta D_{j i t}+V_{i t}-U_{i t}
$$

respectively. $\mathrm{Y}$ is the $\log$ of aggregate crop output, and the five independent variables $\left(\mathrm{x}_{\mathrm{i}}\right)$ are the logs of fertiliser, labour, draft animal power, and land and the time trend. D is the dummy variable used to adjust for the severe floods in 1988. The variables are mean-differenced to allow direct estimation of the output elasticities, as is explained in the results section.

The maximum-likelihood estimates (MLE) of the parameters in the Cobb-Douglas and translog stochastic frontier production function models defined by (6) and (7), given the specifications defined by (1), were obtained using FRONTIER 4.1 (Coelli, 1994). A series of formal hypothesis tests are conducted to determine the preferred functional form and the distribution of the random variables associated with the existence of technical inefficiency and the residual error term.

The results of the hypothesis tests using Likelihood Ratio (LR) tests are presented in Table 1. The first null hypothesis that the Cobb-Douglas production function is an adequate representation for the Bangladesh crop data $\left(\mathrm{H}_{0}: \beta_{\mathrm{ij}}=0, \mathrm{i}, \mathrm{j},=1, \ldots 5\right)$ is strongly rejected, indicating that the translog production function is the preferred model. The second null hypothesis, that there is no technical change over time $\left(\mathrm{H}_{0}: \beta_{5}=\beta_{51}=\beta_{55}=0\right)$ is also strongly rejected by the data, indicating that technological change exists in the Bangladesh crop sector. Thus, the magnitude and direction of technological change will be determined later.

\section{Table 1 here}

The parameter $\gamma\left(\gamma=\sigma^{2}{ }_{u} /\left(\sigma^{2}{ }_{v}+\sigma^{2}\right)\right)$ is the ratio of the error variances from equation (1). 
Thus, $\gamma$ is defined between zero and one, where if $\gamma=0$, technical inefficiency is not present, and where $\gamma=1$, there is no random noise. The test of significance of the inefficiencies in the model $\left(\mathrm{H}_{0}\right.$ : $\gamma=\mu=0)$ is rejected, indicating that it is a significant improvement over an OLS function. The hypothesis that the technical inefficiency effects have a half-normal distribution $\left(\mathrm{H}_{0}: \mu=0\right)$ is also rejected. Finally, the hypothesis that technical inefficiency of the regions are time invariant $\left(\mathrm{H}_{0}: \eta=\right.$ 0 ) is rejected, indicating that technical efficiency levels vary significantly over time.

\section{$5 \quad$ Results}

The parameter estimates for the translog stochastic frontier production function are reported in Table 2. The adjusted R-squared (0.90) obtained from the Ordinary Squares (OLS) estimates, which are used as starting values for the MLEs, indicates that these variables explain $90 \%$ of the variance. A total of 14 coefficients out of 22 are significantly different from zero at the 10 percent level, indicating the importance of some of the interactions and non-linearities among variables. All five direct effects, three squared terms and five cross products have coefficients significantly different from zero. This indicates that rejection of the Cobb-Douglas model as an adequate representation of Bangladesh crop agriculture is justified, because the function is non-linear in some dimensions and there are important interactions among the variables.

\section{Table 2 here}

Whereas for the Cobb Douglas the coefficients are themselves output elasticities (except for the time variable), for the translog the elasticities are functions of the estimated coefficients and the values of the input variables. However, when the mean-differenced variables (that is, $\mathrm{X}_{\mathrm{i}}{ }^{*}=\mathrm{X}_{\mathrm{i}}-$ Xbar) are used in the estimation of the translog function, the output elasticities are again simply the coefficients on the first order terms. All four inputs, land, fertiliser, labour and animal power, appear to be the major determinants of agricultural growth. However, land remains the single most important input with an output elasticity of 0.67 followed by animal power at 0.22 and fertiliser at 
0.13 , respectively. Reasonably enough, for a labour surplus economy, labour has the lowest output elasticity of only 0.08 and indeed is only significantly different from zero at the 10 percent level. The dummy variable, incorporated to capture the drastic fall in output due to floods, is justified as is indicated by the highly significant negative coefficient.

The indicator of returns to scale is the sum of the coefficients on the four conventional inputs, which is 1.10. The null hypothesis of constant returns to scale is rejected in favour of increasing returns, indicating that an increase in farm size will increase production in Bangladesh crop agriculture. ${ }^{2}$

The coefficient on the time-trend variable indicates that there is positive technological progress. The frontier is shifting upwards at an annual rate of 0.28 percent per annum and the effect is non-linear, as is indicated by the significant coefficients on the squared terms. However, the significant negative coefficient on $\eta$ (the time-varying efficiency effect) indicates that technical efficiency is declining over time. The value of $\gamma$ in the diagnosis statistics section is 0.91 and is highly significant. This simple test statistic further reinforces the notion that technical inefficiency in the Bangladesh crop sector is important and the mean response function is not an adequate representation, as was already determined by the LR test reported in Table 1.

\section{Total Factor Productivity and its Decomposition}

The indices for changes in total factor productivity, technical efficiency and technological change for the period from $1960 / 61$ to $1991 / 92$ are presented in Table 3. Technological change was negative until the more rapid diffusion of the modern variety, from 1973. Then, there was improvement in technology, with more rapid progress from 1985 onwards. However, the persistent

\footnotetext{
${ }^{2}$ A simple t-test is used to establish this, but the variance must be calculated from the data. The returns to scale measure is just the sum of elasticities of first order terms (RTS $=\Sigma \lambda \theta$ ), where $\lambda$ is a row vector with 1 corresponding to the elements of $\theta$ (vector of coefficients) and zero everywhere. This, RTS-1is divided by the square root of the covariance matrix $\mathrm{V}(\mathrm{RTS})=\lambda \mathrm{V}(\theta) \lambda$ ' to give the $\mathrm{t}$ test, where $\mathrm{t}=(\mathrm{RTS}-1) /[\mathrm{V}(\mathrm{RTS})]^{1 / 2}$.
} 
decline in efficiency, starting from the late 1970s, becomes the dominant force by the second half of the 1980s. Thus TFP, which was recovering in the late 1970s and early 1980s due to the spread of the modern varieties, declines from its peak to levels lower than ever before.

The indices are constructed from econometric estimates so they tend to show the stylised facts rather than the true situation. The model may well fail accurately to decompose the effects of technological progress and efficiency change. Indeed, although there was some amount of switching from rice to wheat, where all the varieties are modern it is likely that the technological progress index should have ceased growing at the end of the period, as no really new rice varieties were available. This deficiency would result from fitting a parametric function, which is not sufficiently flexible to allow for a further turning point. The efficiency index may also suffer from limitations of this sort. The initial decline in efficiency corresponds to the improvement in the technology index, which is to be expected. Although yields in the most suitable regions continued to rise as the adoption of the modern varieties approached saturation, the same varieties spread to less suitable land, so that the yield of the modern varieties fell. For example, the coastal, central and north-eastern regions have been stagnant in their growth performance since the take-off stage of 'green revolution' and continued to be so although there is no difference in level of technology adoption as compared to other fast growth regions (Ahmed 2001). These regions were historically suitable for traditional varieties but with the gradual displacement to modern varieties whose requirements are different. The more intensive use of modern inputs in these less advantaged areas did not produce the same level of increases in output, so the efficiency differences increased and TFP eventually began to fall.

More confidence can be placed in the TFP index itself and the decline in TFP at the end of the period is the key result. This was exacerbated by the characteristics of the modern varieties, which were fairly typical short-stemmed green revolution varieties. Grain yields were higher, but there was less biomass, so less biological material was returned to the land, either directly, or as animal 
manure. In fact use of lower than recommended level of fertilization is common in Bangladesh. Ahmed (2001) estimated that total levels of fertilizer use for rice production are about $40-45$ percent below the recommended levels. The levels are particularly lower in the use of phosphatic and potassic fertilizers, that are important for preventing sterilization in grains, which need to rise by $60-70$ percent in order to reach the recommended doses (Ahmed, 2001). Hence, in the long run, soil exhaustion begins to play a role in the declining TFP, as more regions suffered from nutrient depletion. Another contributing factor for falling TFP is the re-use of MV rice seeds from one generation to the other, which inherently leads to lower level of productivity since its genetic purity is compromized. Unlike hybrid seeds, which require replacement every year, these self-pollinated non-hybrid MVs enable farmers to use as seeds. But the varietal potency deteriorates overtime as the seeds become mixed with inferior strains owing to cumulative effect of out-crossing (Ahmed, 2001). In principle, these self-pollinated MVs also require replacement in $4-5$ years time to maintain productivity.

\section{Table 3 here}

Figure 1 shows the long-term trends more clearly. The indices are smoothed because they are derived from econometric estimation, but should approximate the actual changes fairly closely. Technological change followed a U-shaped, curve with technical regress until the late 1960s and picked up since then, due to the diffusion of the green revolution technology. As the green revolution technology reached its mature stage in mid-1980s, the technical change curve rose sharply upwards. The combined effect of the persistently declining efficiency levels and the Ushaped technological progress index gives the TFP index, which declined until the mid seventies, recovered with the diffusion of the green revolution technology, but then started to decline again from 1988. By then, the overall rate of efficiency decline, estimated at about 0.47 percent per year, dominated the technological progress effect. The rate of technical progress is estimated at 0.27 percent per annum, conforming with the time-trend coefficient in the production frontier estimation. 
The opposing effects of efficiency decline and technological progress resulted in an estimated decline of TFP at 0.23 percent per year. This net effect of declining TFP reflects the continuing soil nutrient depletion and raises serious concerns regarding the sustainability of the agricultural sector in Bangladesh.

Figure 1 here

\section{$7 \quad$ Factors Explaining TFP, Efficiency and Technical Change}

The region-specific indices of technical efficiency, technical change and TFP are separately regressed on the seven explanatory variables already defined in section 3 . These are the green revolution technology, education, infrastructure, drought proneness, flood proneness, extension expenditures, and research expenditures. The a priori expectation is that green revolution technology, education, infrastructure, extension expenditure and research expenditure will generally have positive influences while flood and drought proneness will have negative influences. The OLS estimates of these explanatory variables on three indices are reported in Table 4, which also confirms the a priori expectations in terms of the direction of these effects.

The contribution of the green revolution technology to efficiency has the expected positive impact and is significant in all three models. Also the level of influence of this variable is highest, revealing its dominant influence on crop agriculture in Bangladesh. Conversely, the infrastructure variable has incorrect signs in all three models and is significant in the technological change and TFP models, with relatively large coefficients. The a priori assumption is that better infrastructure will lead to more effective input delivery, output marketing and information flows, thereby leading to increases in efficiency and hence TFP growth. Instead, the dominant effect of better infrastructure appears to be that it allows the rural population to undertake more non-farm and non-agricultural activities, leading to a negative effect on these indices.

Similarly, education also has incorrect signs throughout and is significant in the TFP model. 
This result was not unexpected since the negative influence of education on crop output, and the adoption of modern agricultural technology, has previously been reported by Deb (1995), Hossain (1989) and Rahman and Shankar (1999). The reason suggested is that higher education provides opportunities for moving away from agriculture, which is less rewarding, and the education system is not oriented to agriculture. The flood proneness variable has the correct negative sign throughout and is significant in the TFP model. Flooding is a natural catastrophe and a regular event in Bangladesh, which frequently significantly damages crop output. The major effect on output was during the nation-wide severe flood of 1988 , which was captured by the dummy in the frontier model as well.

On the other hand, the drought proneness variable has an incorrect significant sign in technical efficiency model, while it has correct signs in the remaining two models, and is a significant influence in the technological change model. The significant positive influence of drought proneness on technical efficiency can be explained with respect to the type of proxy variable used to measure this effect, which is the proportion of area under broadcast Aus rice. As this traditional variety of rice is used with minimum modern input usage, the output potential for this rice varies less with drought levels and this lack of variability results in high technical efficiency. Sharif and Dar (1996) also reported a relatively higher level of technical efficiency in producing traditional rice, as compared with modern varieties.

The extension expenditure and research variables actually restore some confidence in this model, as the results discriminate correctly between the two activities. The effect of extension expenditures should be to move inefficient farmers closer to the frontier and this effect is correctly identified. Research should be affected by feedback from extension and the link to TFP would also be positive in an ideal world. In reality, or at least in many other studies, extension fails to have an effect on TFP and the competition for funds between research and extension could well explain the negative impact on technological change. Similarly, research should have its strongest effect on 
technological change, which is identified, and in this case the effect feeds through into TFP growth, which is also positive. Again, the negative effect on technical efficiency would occur if research and extension compete for a fixed budget.

In short, it can be stated that Green Revolution technology adoption, extension expenditure and drought proneness increases technical efficiency while research expenditure works in opposite direction. On the other hand, Green Revolution technology adoption and research expenditure increases technical progress while infrastructure, education, flood proneness, drought proneness and extension expenditure retards technical progress as well as reducing TFP growth.

\section{Conclusion and Policy Implications}

This paper uses panel data for 31 years to study technical efficiency, technical progress and TFP growth in Bangladesh crop agriculture using a stochastic frontier approach. In this approach, TFP indices are constructed without price data, which are difficult to obtain and often not too reliable in developing countries. The results differ somewhat from the earlier works of Pray and Ahmed (1991) and Dey and Evenson (1991), both for this reason and probably due to differences in the period under consideration.

Despite technological progress following the onset of the Green Revolution, since the 1970s TFP declined over the period, largely due to persistent decline in technical efficiency. Sharif and Dar (1996) indicated relatively lower technical efficiency (81.5 percent) and greater variability in efficiency of modern rice farmers. Deb (1995) also estimated an overall technical efficiency level of 74 percent for rice farmers. Declining TFP raises serious concerns about food security and the sustainability of crop agriculture. However, the high levels of mean technical efficiency of the regions indicate that there is little scope for improving productivity by improving efficiency alone. Thus far, Bangladesh Rice Research Institute (BRRI) released 38 high-yielding varieties in 28 years (Ahmed, 2001) but are poorly disseminated and only limited number of varieties are widely available. Little attention was paid to develop varieties that are suitable for unfavourable regions, 
such as in saline zones and/or elevated regions dependent on monsoon rain. Rice research has paid well in Bangladesh (Ahmed, 2001) and that requires strengthening. Also, effective seed distribution policy to tackle the habit non-replacement of seeds is important to maintain productivity. Investment in irrigation and water control measures, which has been largely dissimilar across regions (Ahmed, 2001), require balancing. Also, balanced and optimal use of fertilizers are necessary in maintaining productivity which can be achieved through appropriate pricing and trade policies that uphold producers' incentives in rice production. Thus, Bangladesh needs policies and actions that can promote new technologies as well as improve efficiency. 


\section{References}

Ahmed A and Sampath R (1992), Effects of Irrigation-Induced Technological Change in Bangladesh Rice Production, American Journal of Agricultural Economics, 74, 144-157

Ahmed A (2001). Retrospects and Prospects of the Rice Economy of Bangladesh. University Press Limited, Dhaka.

Alauddin M and Tisdell C (1991), The Green Revolution and Economic Development: The Process and its Impact in Bangladesh. London: Macmillan

Statistical Yearbook of Bangladesh (1996), Bangladesh Bureau of Statistics, Dhaka

Battese, George and Coelli, Timothy, "A Model for Technical Inefficiency Effects in a Stochastic Frontier Production Function for Panel Data." Empirical Economics, 20, 325-332, 1995.

Coelli T, Rao D and Battese G (1998), An Introduction to Efficiency and Productivity Analysis. Boston: Kluwer Academic Publishers, USA

Coelli T (1994), FRONTIER Version 4.1: A Computer Program for Stochastic Frontier Production and Cost Function Estimation, Department of Econometrics, University of New England, NSW

Deb U (1995), Human Capital and Agricultural Growth in Bangladesh, PhD thesis, Los Banos: University of the Philippines Los Banos

Dey M and Evenson R (1991), The Economic Impact of Rice Research in Bangladesh. Dhaka: BRRI/IRRI/BARC, Bangladesh

Fare R, Grosskopf S and Lovell C Knox (1985), The Measurement of Efficiency of Production, Boston: Kluwer-Nijhoff.

Hossain M (1989), Green Revolution in Bangladesh: Impact on Growth and Distribution of Income, University Press Limited, Dhaka.

Hossain M, Quasem M, Akash M and Jabber M (1990), Differential Impact of Modern Rice Technology: The Bangladesh Case, Bangladesh Institute of Development Studies, Dhaka

McIntire J (1998), The Prospects for Agricultural Growth, in R Faruqee (ed), Bangladesh Agriculture in the $21^{\text {st }}$ Century, The University Press Limited, Dhaka

Pray C and Ahmed Z (1991), Research and agricultural productivity growth in Bangladesh, in Evenson \& Pray (eds) Research and Productivity in Asian Agriculture, Cornell University Press

Rahman S (1999), Socio-economic and Environmental Impacts of Technological Change in Bangladesh Agriculture, PhD thesis, Bangkok: Asian Institute of Technology, Thailand.

Rahman S and Thapa G (1999), Environmental Impacts of Technological Change in Bangladesh Agriculture: Farmers' Perception and Empirical Evidence. Outlook on Agriculture, 28, 233 - 238.

Rahman S and Shankar B (1999), Profits, Supply and HYV Adoption in Bangladesh. Presented at 
the ESRC-DESG Annual Conference on Development Economics for the New Millenium, University of Reading, UK, July, 1999.

Sharif N and Dar A (1996), An Empirical Study of the Patterns and Sources of Technical Inefficiency in Traditional and HYV Rice Cultivation in Bangladesh, Journal of Development Studies, 32, $612-629$ 
Table 1. Hypothesis Tests

\begin{tabular}{|l|c|c|c|c|}
\hline \multicolumn{1}{|c|}{ Null Hypothesis } & Log-likelihood & $\chi^{\mathbf{2}}$ Statistic & Critical $\chi_{\mathbf{v}, \mathbf{0 . 9 5}}$ & Decision \\
\hline Unrestricted model & $\mathbf{7 6 6 . 8 6 1 8}$ & & & \\
\hline (1) $\mathrm{H}_{0}: \beta_{\mathrm{ij}}=0, \mathrm{i}, \mathrm{j},=1, \ldots 5$. & 718.1023 & 97.5190 & $\chi^{2}{ }_{16,0.95}=26.30$ & Reject $\mathrm{H}_{0}$ \\
\hline (2) $\mathrm{H}_{0}: \beta_{5}=\beta_{5 \mathrm{i}}=\ldots \beta_{5 \mathrm{i}}=0$. & 690.2624 & 153.1988 & $\chi^{2}{ }_{6,0.95}=12.59$ & Reject $\mathrm{H}_{0}$ \\
\hline (3) $\mathrm{H}_{0}: \gamma=\mu=0$. & 701.5946 & 130.5346 & $\begin{array}{c}\text { Mixed } \chi_{3,0.95}^{2}= \\
7.05\end{array}$ & Reject $\mathrm{H}_{0}$ \\
\hline (4) $\mathrm{H}_{0}: \mu=0$. & 747.5589 & 38.6058 & $\chi_{1,0.95}^{2}=3.84$ & Reject $\mathrm{H}_{0}$ \\
\hline (5) $\mathrm{H}_{0}: \eta=0$. & 737.1677 & 59.3882 & $\chi_{1,0.95}^{2}=3.84$ & Reject $\mathrm{H}_{0}$ \\
\hline
\end{tabular}

Note: Mixed $\chi_{\mathrm{v}, 0.95}^{2}$ values are taken from Table 1 (Kodde and Palm, 1986). 
Table 2. Stochastic production frontier estimation for Bangladesh crop agriculture.

\begin{tabular}{|c|c|c|}
\hline & \multicolumn{2}{|c|}{ Translog Model } \\
\hline & Coefficient & t-ratio \\
\hline \multicolumn{3}{|l|}{ Production Function } \\
\hline Constant & 9.7514 & $1562.169 * * *$ \\
\hline In Fertilizer & 0.1325 & $9.936 * * *$ \\
\hline In Animals & 0.2179 & $4.892 * * *$ \\
\hline In Labour & 0.0755 & $1.722 *$ \\
\hline ln Land & 0.6741 & $14.016^{* * *}$ \\
\hline Time & 0.0028 & $3.367 * * *$ \\
\hline Fertiliser $^{2}$ & 0.0800 & $1.984 * *$ \\
\hline Animals $^{2}$ & 0.8306 & 1.482 \\
\hline Labour $^{2}$ & 0.4542 & 1.088 \\
\hline Land $^{2}$ & 2.0919 & $2.469 * *$ \\
\hline Time $^{2}$ & 0.0008 & $4.403 * * *$ \\
\hline Fertiliser*Animals & -0.3706 & $-2.686 * * *$ \\
\hline Fertiliser*Labour & -0.1336 & -1.070 \\
\hline Fertiliser*Land & 0.1291 & 0.833 \\
\hline Fertiliser*Time & 0.0001 & 0.048 \\
\hline Animals*Labour & 0.1666 & 0.499 \\
\hline Animals*Land & -1.1004 & $-1.769 *$ \\
\hline Animals*Time & 0.0252 & $3.028 * * *$ \\
\hline Labour*Land & -0.4394 & -0.829 \\
\hline Labour*Time & 0.0095 & 1.295 \\
\hline Land*Time & -0.0212 & $-2.390 * *$ \\
\hline Dummy1989 & -0.1557 & $-11.951 * * *$ \\
\hline \multicolumn{3}{|l|}{ Diagnosis statistics } \\
\hline Sigma-squared & 0.0165 & $6.950 * * *$ \\
\hline Gamma & 0.9063 & $48.130 * * *$ \\
\hline $\mathrm{Mu}$ & 0.0698 & 0.506 \\
\hline Eta & -0.2112 & $-7.898 * * *$ \\
\hline Log-likelihood & 766.8618 & - \\
\hline Adjusted $\mathrm{R}^{2}$ from OLS & 0.90 & - \\
\hline Number of observations & 496 & - \\
\hline Number of years & 31 & - \\
\hline Number of regions & 16 & - \\
\hline
\end{tabular}

Note: $* * *=$ significant at 1 percent level $(\mathrm{p}<0.01)$.

$* *=$ significant at 5 percent level $(\mathrm{p}<0.05)$.

$*$ = significant at 10 percent level $(\mathrm{p}<0.10)$. 
Table 3. Total factor productivity change, technical efficiency change and technical change using a stochastic frontier approach.

\begin{tabular}{|c|c|c|c|}
\hline Year & Efficiency change & Technical change & $\begin{array}{c}\text { Total factor } \\
\text { productivity change }\end{array}$ \\
\hline 1961 & 1.0000 & 1.0000 & 1.0000 \\
\hline 1962 & 0.9999 & 0.9905 & 0.9905 \\
\hline 1963 & 0.9999 & 0.9820 & 0.9819 \\
\hline 1964 & 0.9998 & 0.9742 & 0.9740 \\
\hline 1965 & 0.9996 & 0.9672 & 0.9669 \\
\hline 1966 & 0.9995 & 0.9612 & 0.9607 \\
\hline 1967 & 0.9993 & 0.9557 & 0.9550 \\
\hline 1968 & 0.9991 & 0.9508 & 0.9499 \\
\hline 1969 & 0.9988 & 0.9466 & 0.9455 \\
\hline 1970 & 0.9984 & 0.9432 & 0.9417 \\
\hline 1971 & 0.9980 & 0.9408 & 0.9389 \\
\hline 1972 & 0.9975 & 0.9397 & 0.9373 \\
\hline 1973 & 0.9968 & 0.9398 & 0.9368 \\
\hline 1974 & 0.9960 & 0.9410 & 0.9372 \\
\hline 1975 & 0.9950 & 0.9428 & 0.9380 \\
\hline 1976 & 0.9937 & 0.9455 & 0.9395 \\
\hline 1977 & 0.9922 & 0.9492 & 0.9417 \\
\hline 1978 & 0.9903 & 0.9535 & 0.9443 \\
\hline 1979 & 0.9879 & 0.9586 & 0.9471 \\
\hline 1980 & 0.9851 & 0.9645 & 0.9501 \\
\hline 1981 & 0.9815 & 0.9711 & 0.9531 \\
\hline 1982 & 0.9772 & 0.9785 & 0.9561 \\
\hline 1983 & 0.9718 & 0.9865 & 0.9587 \\
\hline 1984 & 0.9652 & 0.9954 & 0.9608 \\
\hline 1985 & 0.9572 & 1.0051 & 0.9620 \\
\hline 1986 & 0.9473 & 1.0156 & 0.9620 \\
\hline 1987 & 0.9353 & 1.0273 & 0.9608 \\
\hline 1988 & 0.9206 & 1.0402 & 0.9576 \\
\hline 1989 & 0.9029 & 1.0541 & 0.9517 \\
\hline 1990 & 0.8814 & 1.0690 & 0.9422 \\
\hline 1991 & 0.8556 & 1.0849 & 0.9283 \\
\hline Mean & 0.9742 & 0.9790 & 0.9537 \\
\hline
\end{tabular}


Table 4. Factors explaining changes in technical efficiency, technical change and total factor productivity in Bangladesh crop sector.

\begin{tabular}{|c|c|c|c|c|c|c|}
\hline \multirow[t]{3}{*}{ Regressors } & \multicolumn{6}{|c|}{ Dependent variables } \\
\hline & \multicolumn{2}{|c|}{ Model 1} & \multicolumn{2}{|c|}{ Model 2} & \multicolumn{2}{|c|}{ Model 3} \\
\hline & $\begin{array}{l}\text { Technical } \\
\text { efficiency } \\
\text { index }\end{array}$ & $\begin{array}{c}\text { Expected } \\
\text { sign }\end{array}$ & $\begin{array}{l}\text { Technical } \\
\text { change } \\
\text { index }\end{array}$ & $\begin{array}{l}\text { Expected } \\
\text { sign }\end{array}$ & $\begin{array}{l}\text { Total factor } \\
\text { productivity } \\
\text { index }\end{array}$ & $\begin{array}{l}\text { Expected } \\
\text { sign }\end{array}$ \\
\hline Constant & $\begin{array}{c}0.98345 \\
(91.519) * * *\end{array}$ & & $\begin{array}{c}1.05180 \\
(63.390)^{* * *}\end{array}$ & & $\begin{array}{c}1.06160 \\
(67.989)^{* * *}\end{array}$ & \\
\hline $\begin{array}{l}\text { Green Revolution } \\
\text { technology }\end{array}$ & $\begin{array}{c}0.15571 \\
(4.663) * * *\end{array}$ & $\sqrt{ }$ & $\begin{array}{c}0.26400 \\
(3.948)^{* * *} \\
\end{array}$ & $\sqrt{ }$ & $\begin{array}{c}0.22139 \\
(3.458)^{* * *} \\
\end{array}$ & $\sqrt{ }$ \\
\hline Infrastructure & $\begin{array}{l}-0.01459 \\
(-0.636)\end{array}$ & $\mathrm{x}$ & $\begin{array}{c}-0.22889 \\
(-4.841)^{* * *}\end{array}$ & $\mathrm{x}$ & $\begin{array}{c}-0.14535 \\
(-3.193)^{* * *}\end{array}$ & $\mathrm{x}$ \\
\hline Education & $\begin{array}{l}-0.00104 \\
(-0.274) \\
\end{array}$ & $\mathrm{x}$ & $\begin{array}{l}-0.01058 \\
(-1.518) \\
\end{array}$ & $\mathrm{x}$ & $\begin{array}{c}-0.04281 \\
(-6.506)^{* * *}\end{array}$ & $\mathrm{x}$ \\
\hline Flood proneness & $\begin{array}{l}-0.00951 \\
(-0.904) \\
\end{array}$ & $\sqrt{ }$ & $\begin{array}{l}-0.03262 \\
(-1.424) \\
\end{array}$ & $\sqrt{ }$ & $\begin{array}{c}-0.05671 \\
(-2.531)^{* *}\end{array}$ & $\sqrt{ }$ \\
\hline Drought proneness & $\begin{array}{c}0.06820 \\
(4.415)^{* * *}\end{array}$ & $\mathrm{x}$ & $\begin{array}{c}-0.12641 \\
(-4.324)^{* * *}\end{array}$ & $\sqrt{ }$ & $\begin{array}{l}-0.04494 \\
(-1.620)\end{array}$ & $\sqrt{ }$ \\
\hline \begin{tabular}{|l} 
Extension \\
expenditure
\end{tabular} & $\begin{array}{c}0.00065 \\
(3.592)^{* * *}\end{array}$ & $\sqrt{ }$ & $\begin{array}{c}-0.00134 \\
(-7.227)^{* * *} \\
\end{array}$ & $\mathrm{x}$ & $\begin{array}{c}-0.00046 \\
(-2.797)^{* * *}\end{array}$ & $\mathrm{x}$ \\
\hline $\begin{array}{l}\text { Research } \\
\text { expenditure }\end{array}$ & $\begin{array}{c}-0.00001 \\
(-6.404)^{* * *}\end{array}$ & $\mathrm{x}$ & $\begin{array}{c}0.00001 \\
(4.780)^{* * *}\end{array}$ & $\sqrt{ }$ & $\begin{array}{c}0.00001 \\
(2.743)^{* * *}\end{array}$ & $\sqrt{ }$ \\
\hline Adjusted $\mathrm{R}^{2}$ & 0.46 & & 0.29 & & 0.10 & \\
\hline $\mathrm{F}_{(7,488)}$ statistic & $62.16 * * *$ & & $29.54 * * *$ & & $8.89 * * *$ & \\
\hline D.W. Statistics & 1.96 & & 1.98 & & 2.07 & \\
\hline
\end{tabular}

Note: The estimates for Model 1 and Model 2 are corrected for first order autocorrelated disturbances using Prais-Winsten method.

$* * *=$ significant at 1 percent level $(\mathrm{p}<0.01)$.

$* *=$ significant at 5 percent level $(\mathrm{p}<0$ 


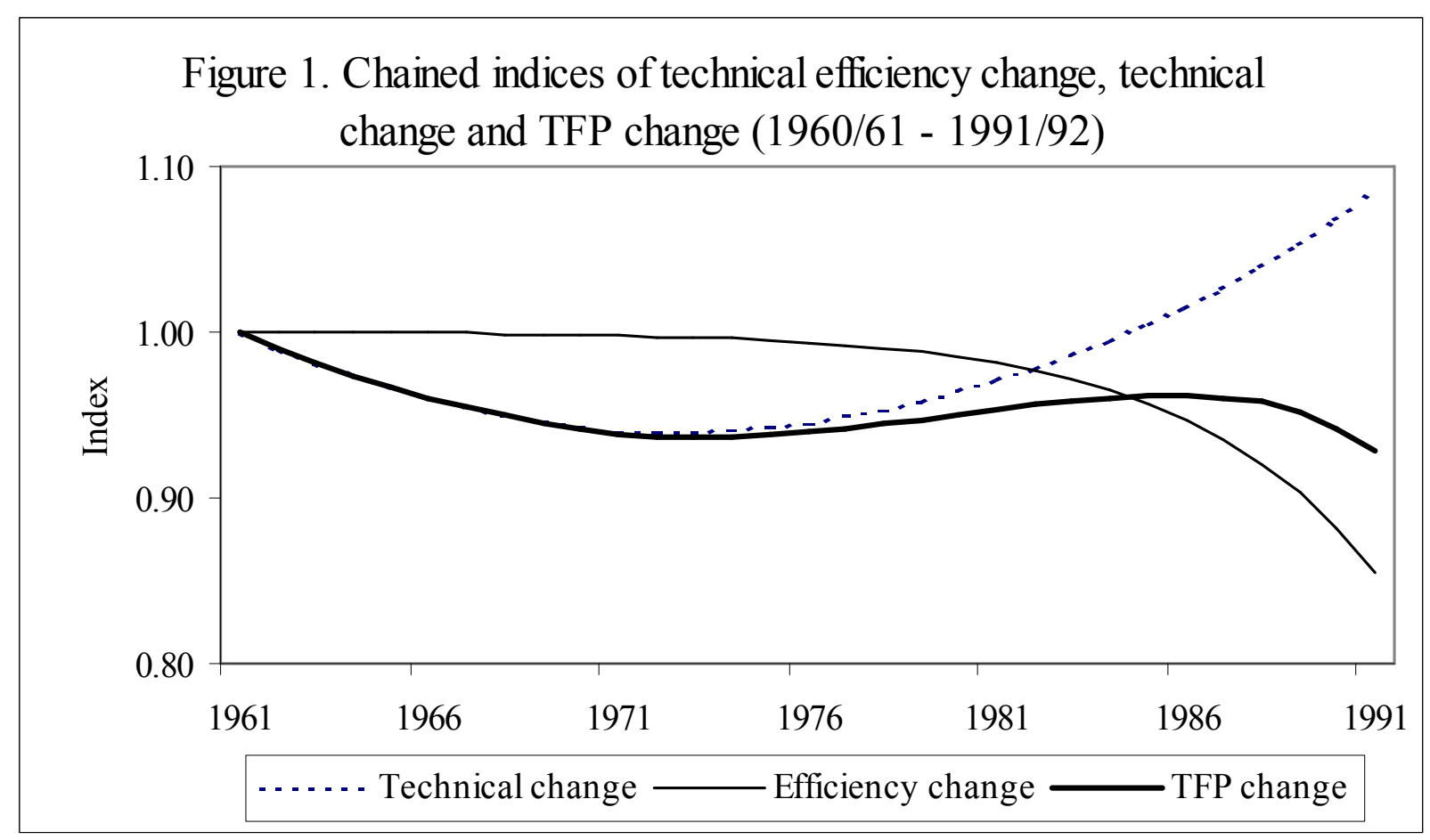

